\title{
Transoral Approach to CT-Guided C2 Interventions
}

Arra S. Reddy, MD, Diane DiNobile, NP, Juan E. Ortega, MD, and Nagamani Peri, MD

From: Beth Israel Deaconess

Medical Center, Boston, MA.

Dr. Reddy and Ms. DiNobile are with the Division of Interventional Radiology, Department of Radiology, Beth Israel Deaconness Medical Center, Boston, MA.

Drs. Ortega, and Peri are with the Division of Neuroradiology,

Department of Radiology, Interventional Neuradiology, Beth Israel Deaconness Medical Center, Boston, MA.

Address correspondence: Arra Suresh Reddy, MD Dept. of Radiology, Interventional

Neuroradiology Division Beth Israel Deaconess Medical Center

330 Brookline Avenue, CC $327 \mathrm{C}$ Boston, MA 02215 Email:

sreddy1@bidmc.harvard.edu

Disclaimer: There was no external funding in the preparation of this manuscript.

Conflict of interest: None.

Manuscript received: 07/10/2008 Revised manuscript received: $10 / 08 / 2008$

Accepted for publication: 11/10/2008

Free full manuscript:

www.painphysicianjournal.com
Background: Lesions involving C2 are unique as it is challenging to approach these lesions. The transoral approach to C2 lesions has been extensively used by surgeons and increasingly used by interventional radiologists for vertebroplasty as it is safer and less demanding than other approaches like anterolateral and posterolateral (transpedicular). However, using this approach for image-guided biopsies is little described in literature with a few cases described so far being under fluoroscopic guidance. We describe a series of 5 procedures using transoral approach -4 biopsies (and one vertebroplasty that was published earlier) on C2 lesions under CT guidance. To our knowledge, our series is the first one where the transoral biopsies were performed using Computed Tomography (CT) guidance.

Objective: To describe our initial experience with the transoral approach to image-guided biopsies on C2 vertebra and its relative advantages and disadvantages.

Methods: We performed 5 procedures -4 biopsies (and one vertebroplasty published earlier) on different types of lesions involving C2, through the transoral approach, using CT guidance under general anesthesia and appropriate precautions to reduce potential complications like infection, hemorrhage, etc.

Results: The procedures were well tolerated by the patients without any complications, immediately as well as at follow-up. All the biopsies in our series were technically successful without any minor or major complications. The biopsy yield was $50 \%$ which may be due to the thinner needles used.

Conclusion: CT-guided transoral approach to biopsies on C2 lesions is a direct, safe, and precise technique when performed with appropriate precautions.

Key words: Transoral, C2, image-guided, CT-guided, interventions, biopsy

Pain Physician 2009; 12:1:253-258 esions involving the dens and body of $\mathrm{C} 2$ are unique as it is quite challenging to

approach these lesions for surgery or other interventions due to the close proximity to several important neural and vascular structures. There are 3 different approaches to C2 lesions - anterolateral, posterolateral (transpedicular), and transoral.
The different approaches are depicted in Fig. 1. The anterolateral and posterolateral (transpedicular) approaches are technically demanding due to the presence of adjacent vascular and neural structures and the small size of the pedicles of $\mathrm{C} 2$. The transoral approach eliminates this risk and has been used extensively by surgeons. There has also been a growing 


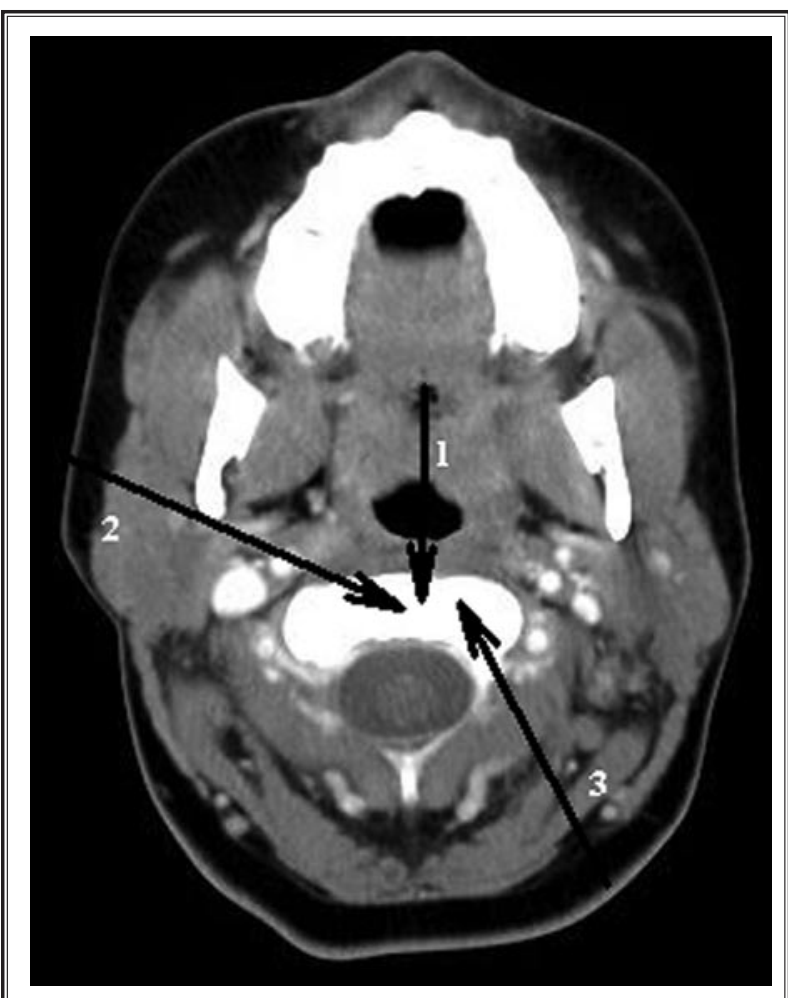

Fig. 1. Different approaches to C2 body/dens lesions. 1. Transoral; 2. Anterolateral; 3. Posterolateral

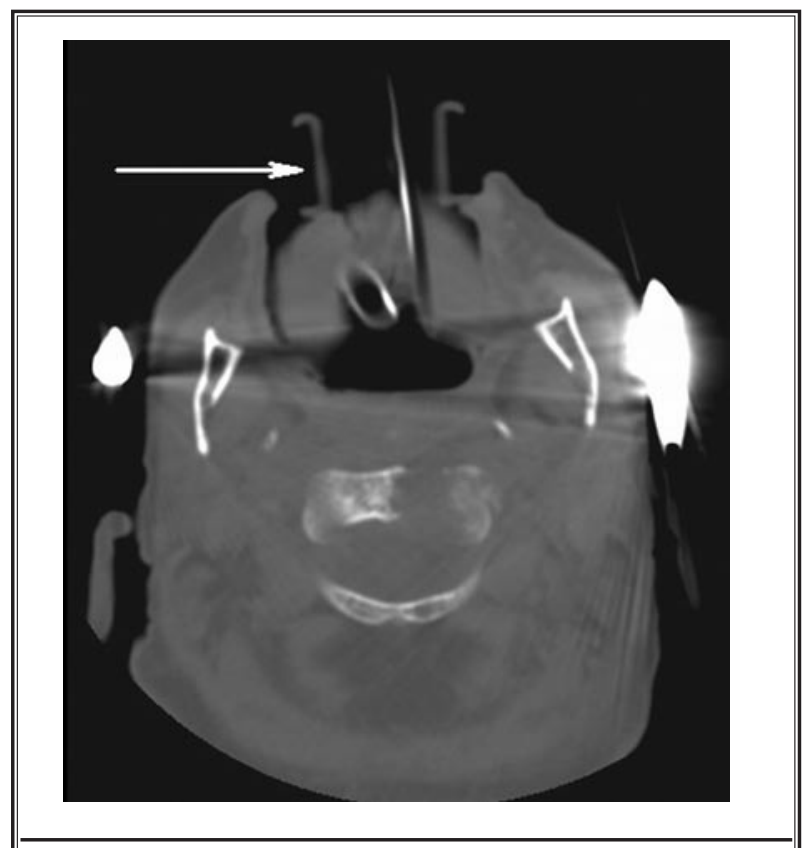

Fig. 2. Transoral biopsy of C2 lesion (Case 2). ArrowDingman retractor in place to keep the mouth open. popularity of the transoral approach among interventional radiologists. It has been predominantly used for performing vertebroplasty on various types of lytic lesions. However, use of this approach for performing image-guided biopsies is less described in literature, with the few cases described so far being under the guidance of fluoroscopy. We describe our experience with this technique for performing Computed Tomography (CT) guided biopsies on C2 lesions.

\section{Methods}

From 2002 to 2008, we performed 5 procedures on C2 lesions using the transoral approach. Of these, 4 were biopsies using the transoral approach under CT guidance on 4 patients ranging in age from 59 to 76 years. In one of the patients, we also performed vertebroplasty using a transoral approach (along with a biopsy of the lesion) and was published earlier.

The usual pre-procedure precautions like the coagulation profile, preanesthetic consult, and consent were obtained. Prophylactic antibiotics, Cefazolin (Ancef), one gram was administered intravenously an hour before the procedure and continued post-procedure for 3 to 5 days. The procedure was performed under general anaesthesia using orotracheal intubation with the. patient in the supine position and head slightly extended to make the approach easier. Vital parameters were continuously monitored.

A pre-procedure non-contrast $\mathrm{CT}$ was performed from skull base to $\mathrm{C} 3$ vertebra and $3 \mathrm{~mm}$ thin axial images was obtained. Later, a self-retaining retractor (Dingman; V Mueller, Cleveland, Ohio) was applied to depress the tongue and displace the endotracheal tube from the field (Fig. 2). The oropharynx was disinfected with Povidone iodine. One percent lidocaine mixed with epinephrine was then injected submucosally to provide local anesthesia and vasoconstriction.

Under CT guidance, a 22-gauge spinal needle covered by an outer plastic sheath was utilized as an initial guidance to establish the route of access to the lesion. The needle was advanced between the tongue and uvula towards the posterior pharyngeal wall through the retropharyngeal space and the prevertebral muscles into the target lesion in the C2 vertebra. Using the established route, a 17-gauge Introducer needle was placed at the edge of the target lesion. Utilizing the trocar of the 17-gauge Introducer needle, a 20-gauge Franseen needle (Allegiance, McGaw Park, IL) was inserted to obtain tissue samples (Figs. 3 and 4). 


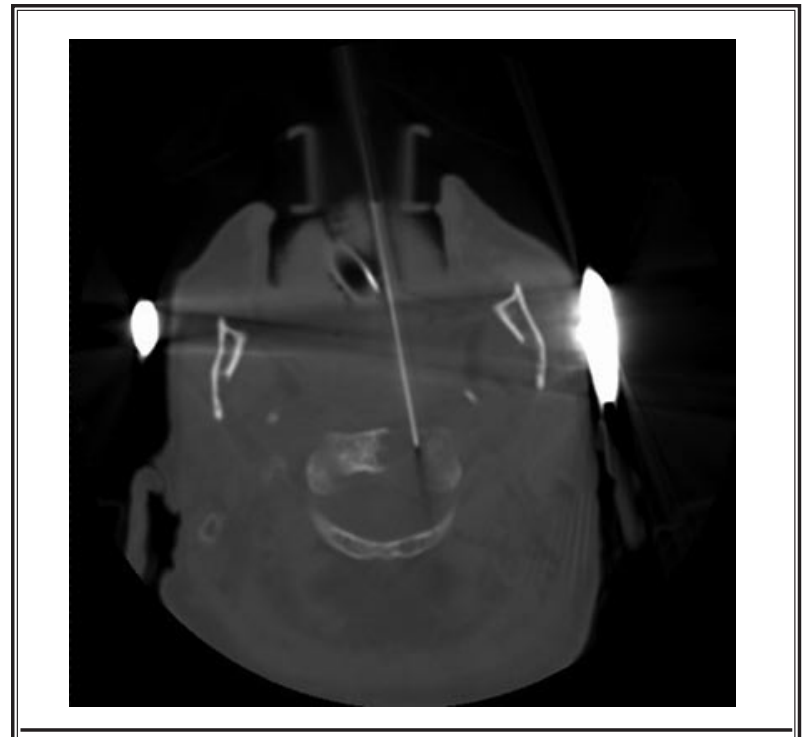

Fig. 3. Transoral biopsy of C2 lesion (Case 2). A 20gauge Franseen needle placed into the lesion for fine needle aspiration and core biopsy.

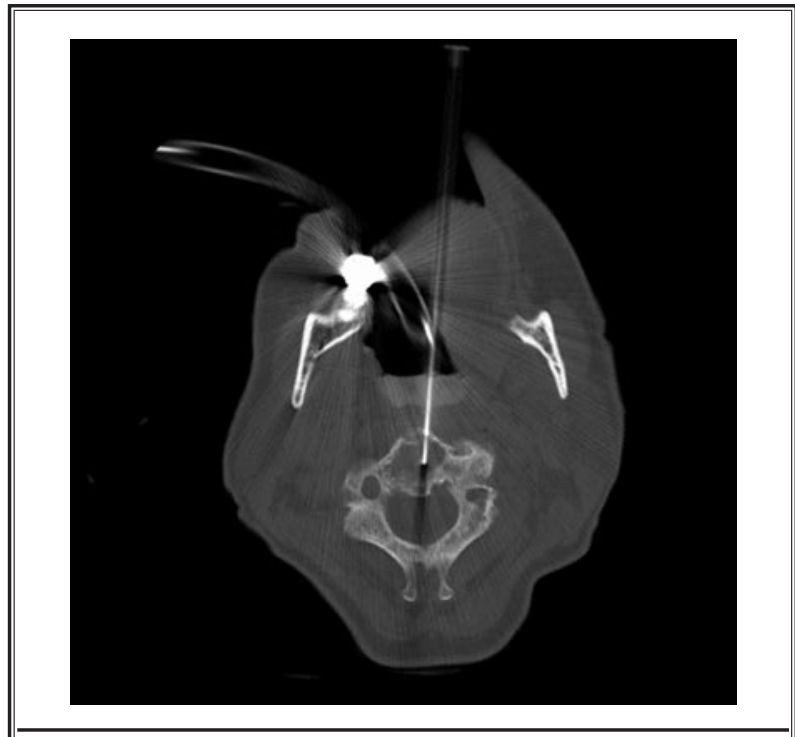

Fig. 4. Transoral biopsy of C2 lesion (Case 4). A 20gauge Franseen needle placed into the lesion for fine needle aspiration and core biopsy.
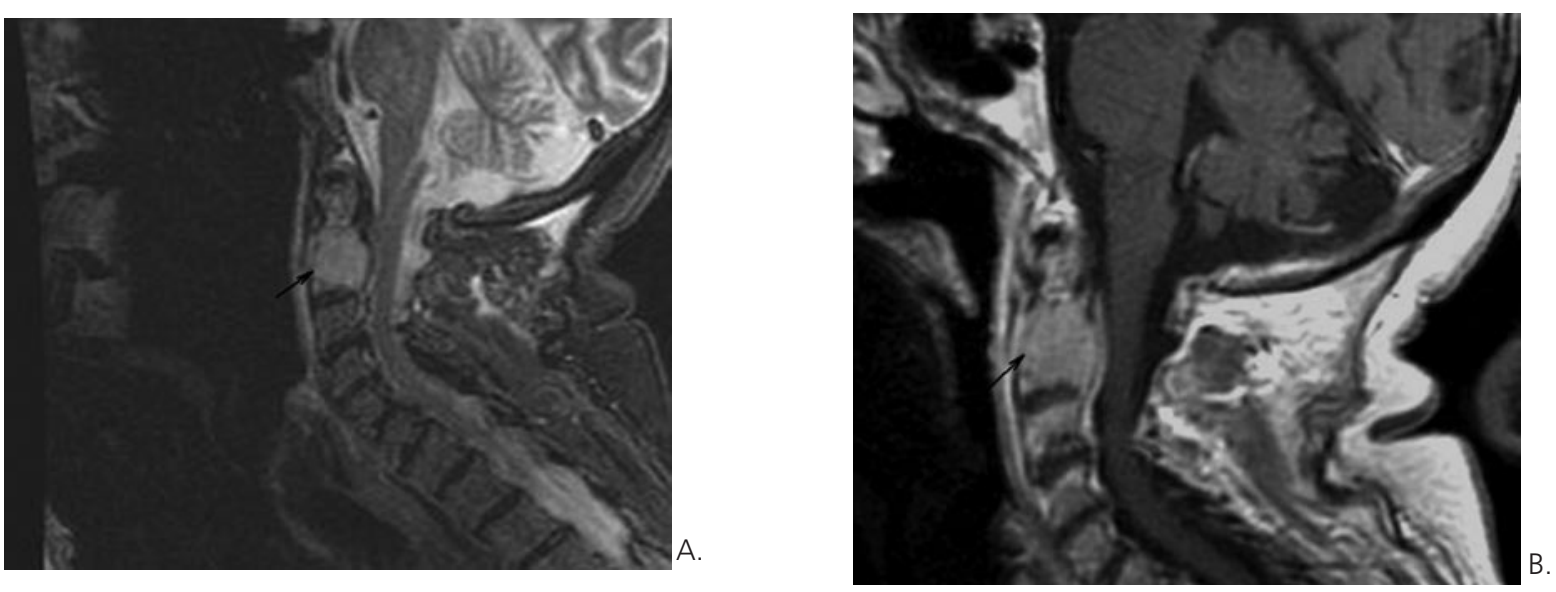

Fig. 5. MRI of Case 2. (A) Sagittal STIR image showing an expansile, homogeneous, hyperintense lesion involving C2 body - (arrow). (B) Sagittal postcontrast T1W image shows homogeneous enhancement of the lesion (arrow). Biopsy revealed a few atypical cells and was non-diagnostic.

\section{Results}

CASE 1: A 74-year-old male patient with worsening neck pain for 4 months. The MRI revealed a large heterogeneous lesion involving $\mathrm{C} 2$.

CASE 2: A 76-year-old female patient with increasing neck pain for 3 months. The MRI showed an expansile, homogeneous, enhancing lesion in C2 (Fig. 5).

CASE 3: A 74-year-old male patient with acute neck pain. The MRI revealed a large heterogeneous mildly enhancing lesion in $\mathrm{C} 2$.

CASE 4: A 59-year-old female patient with neck pain for several months. The MRI revealed a large expansile homogeneously enhancing lesion in C2 (Fig. 6).

All the lesions were lytic on CT scan.

Table 1 depicts the biopsy results in our series. 

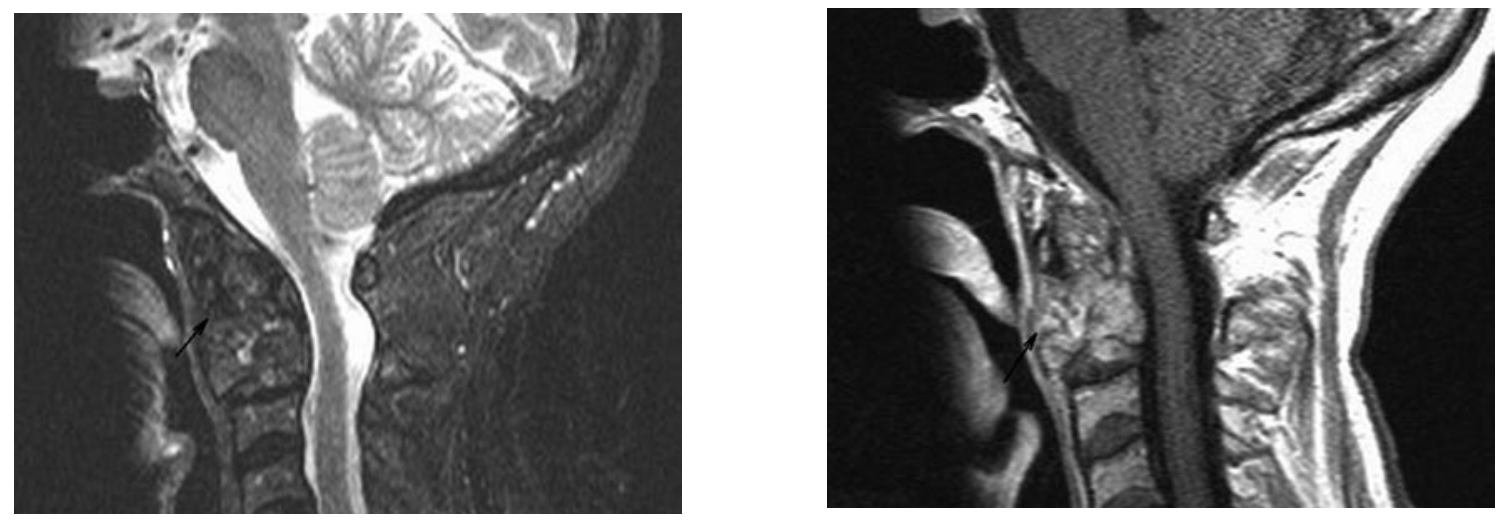

A.

Fig. 6. MRI of Case 4. (A) Sagittal STIR image shows a large, expansile hypointense lesion involving C2 (arrow). (B) Sagittal postcontrast $T 1 W$ image shows moderate enhancement in the lesion (arrow). Unlike most tumors that are hyperintense on STIR sequence, this lesion is hypointense indicating a fibrous component in the lesion. Though the biopsy was unremarkable, histopathology after surgical resection was fibrous dysplasia, which is a rare lesion in C2.

Table 1. Transoral CT-guided biopsy results in our series.

\begin{tabular}{|c|c|c|c||}
\hline No. (Age/Gender) & Transoral Biopsy Result & $\begin{array}{c}\text { Complications } \\
\text { related to transoral } \\
\text { procedure }\end{array}$ & Comments \\
\hline $1.74 / \mathrm{M}$ & Non-specific inflammatory cells & $\begin{array}{c}\text { None at 6-month } \\
\text { follow-up \& later }\end{array}$ & Pt. also had transoral vertebroplasty and relief of pain \\
\hline $2.76 / \mathrm{F}$ & A few atypical epithelial cells & None & $\begin{array}{c}\text { Treated with external beam radiotherapy; pain } \\
\text { relieved }\end{array}$ \\
\hline $3.74 / \mathrm{M}$ & No grossly identifiable tissue & None & $\begin{array}{c}\text { Negative systemic work up; pain improved with } \\
\text { conservative management }\end{array}$ \\
\hline $4.59 / \mathrm{F}$ & $\begin{array}{c}\text { Unremarkable skeletal muscle, } \\
\text { fibrous tissue and fibrocartilage }\end{array}$ & None & $\begin{array}{c}\text { Surgical resection performed; the lesion was fibrous } \\
\text { dysplasia, which is a very rare lesion in C2. }\end{array}$ \\
\hline
\end{tabular}

\section{Discussion}

The transoral approach to $\mathrm{C} 2$ is a safe and direct approach and has been used by surgeons and also interventional radiologists. It has been used for vertebroplasty for various types of C2 lytic lesions like metastases, myeloma, aneurysmal bone cyst, and osteoporotic fracture (1-6). However, use of this technique for image-guided biopsy of $\mathrm{C} 2$ lesions is a novel technique and is less described in literature $(7,8)$.

There are 3 different approaches to lesions involving the $\mathrm{C} 2$ body and dens - anterolateral, posterolateral, and transoral (Fig. 1).
The anterolateral approach requires extension of the head to elevate the mandible allowing an easier approach to the C2 vertebral body. Initially, the carotid artery is located by palpation, and the carotid space is displaced laterally by the operator's hand; then the needle is placed approximately $1 \mathrm{~cm}$ below the angle of the mandible anterolateral to the visceral space, advanced carefully in an oblique (posterior, cranial, and medial) direction and advanced progressively through the parapharyngeal, retropharyngeal, and prevertebral spaces, into the $\mathrm{C} 2$ body and dens. However, care should be taken to avoid injury to the submandibular 
gland and the structures of the carotid space (jugular vein, carotid artery, and cranial nerves). Mont'Alverne et al (9) reported the use of this approach for vertebroplasty for $\mathrm{C} 2$ lesions in 12 patients. Though the complications were related to cement leakage in their series, the authors agree that it is a challenging procedure that may carry a risk to neighboring structures, such as the carotid and vertebral arteries, with potential intracranial complications.

The posterolateral approach to the $\mathrm{C} 2$ is through the posterolateral tissues and pedicle of the C2 into the body of the $\mathrm{C} 2$. While this approach is easy in the thoracic and lumbar regions, it is difficult in the upper cervical spine due to the small size of the pedicles which increases the risk of injury to neural structures (8).

In contradistinction, the transoral approach provides direct access to $\mathrm{C} 2$ body lesions without the risk of injury to neural or vascular structures.

The transoral C2 guided-biopsies described so far in literature were performed using fluoroscopic guidance. In our series, we used CT guidance for all the procedures and one case was performed using DYNA $\mathrm{CT}$, combining $\mathrm{CT}$ and fluoroscopy. To our knowledge, our series is the first in literature describing transoral image-guided biopsies under CT guidance. Though fluoroscopy provides greater real time guidance, CT provides guidance for more accurate needle placement.

The samples had enough material in $50 \%$ of our cases. Insufficient material for adequate diagnosis may be related to the size of the needle (20G) that was used for core biopsy. However, Gabrillargues and Michel (8) described 3 cases of transoral C2 biopsy using fluoroscopic guidance and $13 \mathrm{G}$ needle with a yield of $100 \%$ without any associated complications. Table 2 shows the different types of needles used by various authors in literature and their results. The lower yield in our series can be due to the thinner needle used. As larger needles were safely used by various authors earlier, it is probably safe to use larger needles even in the presence of lytic lesions and can result in higher diagnostic yield.

\section{Complications}

Complications that can be associated with transoral procedures are infection, hemorrhage, and those related to general anesthesia. Infection (including retropharyngeal abscess, meningitis, and encephalitis) has been the most important complication in the past with transoral procedures (3). The infection rate for open transoral surgical procedures has been reported to be between $0-6.5 \%$ recently (1) and much higher in the remote past. The exact incidence of complications with transoral image-guided procedures is difficult to assess from the existing literature as these are mostly isolated case reports. Minimal leakage of cement has been reported by Sachs et al (2) during transoral vertebroplasty. However, no complications were reported with transoral image-guided biopsies by Gabrillargues and Michel (8).

\section{Methods to Decrease Risk of Infection}

As infection is one of the serious complications that can be prevented, precautionary measures to reduce this complication are of utmost importance as with any interventional procedure. Aseptic precautions, use of peri-procedural prophylactic antibiotics, and the use of thinner needles covered with plastic sleeves are some of the methods that should be routinely employed. If vertebroplasty is also performed, mixing the polymethylmethacrylate cement (PMMA) with antibiotics can help reduce the risk of infection. There have been different opinions regarding the role

Table 2. Biopsy needles used and yield by various authors for image-guided transoral biopsies.

\begin{tabular}{|l|c|c|c|c|c|c||}
\hline Author & $\begin{array}{c}\text { No. } \\
\text { of } \\
\text { cases }\end{array}$ & $\begin{array}{c}\text { Type of transoral } \\
\text { procedure } \\
\text { Bx / VP }\end{array}$ & Needle size & Biopsy yield & Complications & $\begin{array}{c}\text { Comments } \\
\text { (Guidance) }\end{array}$ \\
\hline $\begin{array}{l}\text { Gabrillargues and } \\
\text { Michel (8) }\end{array}$ & 3 & $3 \mathrm{Bx} ; 1 \mathrm{VP}$ & $13 \mathrm{G}$ & $100 \%$ & None & Fluoro \\
\hline Gailloud et al (4) & 1 & $1 \mathrm{Bx} \& \mathrm{VP}$ & $16 \mathrm{G}$ & $100 \%$ & None & Fluoro \\
\hline Beall et al (5) & 1 & $1 \mathrm{VP}$ & $11 \mathrm{G}$ & NA & None & Fluoro \\
\hline Current series & 5 & $\begin{array}{c}3 \mathrm{Bx} \\
1 \mathrm{Bx} \text { and VP }\end{array}$ & $\begin{array}{c}20 \mathrm{G} \\
13 \mathrm{G}\end{array}$ & $50 \%$ & & CT \\
\hline
\end{tabular}

Bx - Biopsy; VP - Vertebroplasty; NA - not available 
Table 3. Summary of different approaches to C2 lesions.

\begin{tabular}{|l|c|c|c||}
\hline PARAMETER & ANTEROLATERAL & POSTEROLATERAL & TRANSORAL \\
\hline Anaesthesia & Local & Local & General \\
\hline Risk of neuro \& vascular injury & High & High & Low/ None $[2,4,5,8,10]$ \\
\hline Ease of technique & Less easy & Less easy & More easy $[4]$ \\
\hline
\end{tabular}

of the cement-antibiotic mixture in preventing infection following vertebroplasty. Maintaining a sterile field is often a problem with the transoral approach (10). Routine use of a cement-antibiotic mixture has been advocated by some radiologists and surgeons (11-13). While some practitioners advocate the routine use of intravenous antibiotics, others reserve the use of these for immunocompromised patients (14).

\section{Comparison of Different Approaches to C2}

To our knowledge, there have been no studies directly comparing the yield and complications of the 3 different approaches to lesions involving the $\mathrm{C} 2$ body and dens. There are isolated case reports and review articles describing the various approaches; however, the advantages and disadvantages of the different approaches have been described by several authors. The risk of neurovascular injury is high with the anterolateral and posterolateral approaches, which is obvious from the regional anatomy and the direction of the needle in these approaches. The transoral approach has less or no risk of neurovascular injury as there are no vital structures along the trajectory of the needle $(2,4,5,8,10)$. The transoral approach is also less demanding technically, from our own experience as well as according to Gailloud et al (4).

Table 3 summarizes the advantages and disadvantages of the different approaches to $\mathrm{C} 2$ lesions.

\section{Conclusion}

The CT-guided transoral approach to biopsies on C2 lesions is a direct, safe, and precise technique when performed with appropriate precautions.

\section{References}

1. Martin JB, Gailloud P, Dietrich P, Luciani $M$, Somon T, Rüfenach D. Direct transoral approach to C2 percutaneous vertebroplasty. Cardiovasc Intervent Radiol 2002; 25:517-519.

2. Sachs D, Inamasu J, Mendel EE, Guiot $\mathrm{BH}$. Transoral vertebroplasty for renal metastasis involving the axis. Spine 2006; 31:E925-E928.

3. Tong F, Cloft H, Joseph G, Rodts G, Dion J. Transoral approach to cervical vertebroplasty for multiple myeloma. $A J R$ 2000; 175:1322-1324.

4. Gailloud P, Martin JB, Olivi A, Rufenacht DA, Murphy KJ. Transoral vertebroplasty for a fractured C2 aneurysmal bone cyst. J Vasc Interv Radiol 2002; 13:340341.

5. Beall DP, Stanfield M, Martin HD, Stapp AM. Transoral vertebral augmentation with polymethylmethacrylate in the treatment of a patient with a dens fracture nonunion and subarticular verte- bral body fracture of C2. Skeletal Radiol 2007; 36:453-458.

6. Reddy AS, Hochman M, Loh S, Rachlin J, Li J, Hirsch JA. CT guided transoral approach to C2 percutaneous vertebroplasty. Pain Physician 2005; 8:235238.

7. Patil AA. Transoral stereotactic biopsy of the second cervical vertebral body: Case report with technical note. Neurosurgery 1989; 25:999-1002.

8. Gabrillargues J, Michel J. Interventional radiology: Transoral approach to $\mathrm{C} 2$. J Radiology 2008; 89:245-249.

9. Mont'Alverne F, Vallée JN, Cormier E, Guillevin R, Barragan H, Jean B, Rose M, Chiras J. Percutaneous vertebroplasty for metastatic involvement of the axis. AJNR 2005; 26:1641-1645.

10. Gupta S, Henningsen JA, Wallace MJ, Madoff DC, Morello FA, Ahrar K, Murthy R, Hicks ME. Percutaneous biopsy of head and neck lesions with CT guid- ance: Various approaches and relevant anatomic and technical considerations. Radiographics 2007; 27:371-390.

11. Kallmes DF, Jensen ME. Percutaneous vertebroplasty. Radiology 2003; 229:27-36.

12. Shapiro SA. Cranioplasty, vertebral body replacement, and spinal fusion with tobramycin-impregnated methylmethacrylate. Neurosurgery 1991; 28:789-791.

13. Weiner J. Vertebroplasty: Non-surgical treatment of compression fractures. Boca Radiology Group web site. http:// bocaradiology.com/Procedures/Vertebroplasy/Vertebroplasty.html.

14. Mathis JM, Barr JD, Belkoff SM, Barr MS, Jensen ME, Deramond H. Percutaneous vertebroplasty: A developing standard of care for vertebral compression fractures. AJNR Am J Neuroradiol 2001; 22:373-381. 